\section{Effect of cage confinement on social behavior in squirrel monkeys*}

\author{
S. J. TARANTINO \\ Florida Atlantic University, Boca Raton, Fla. 33432
}

Data on the effects of cage confinement in squirrel monkeys was obtained as part of a larger study on social perception. Approach-withdrawal behavior was studied at three intervals over a 6-month period, during which the animals were confined in individual cages. At the sixth month a noticeable change in behavior occurred. During 20-min test intervals the animals displayed very strong attachment behavior. This was in marked contrast to their earlier behavior.

As the experimental study of primate social behavior increases, the effect on such behavior of keeping animals confined for such experiments becomes of crucial concern. Though other investigators (e.g., Mason, 1960, 1961a;b; Moyer, 1965; Joslyn, 1968; and Salazar, 1968) have studied the effects of "social restriction" or "isolation" on the behavior of monkeys and rats, these studies have been usually concerned with early social restriction or isolation in a developmental sense. In such experiments animals were isolated from other animals of their species at some stage of development, then their behavior, along various dimensions, was compared with the behavior of animals that had not been isolated. The experiment reported here is different in that it is concerned with the changes in social relations (specifically, approach-withdrawal tendencies) in animals that had been confined for relatively long periods of time. The data reported here were obtained as part of a larger study on social perception in squirrel monkeys.

\section{SUBJECTS}

The Ss were six squirrel monkeys obtained from the primate colony at Florida Atlantic University. Their mean estimated age at the beginning of the experiment was 14 months. All were males. These animals were born and reared in the colony and were socially experienced members of groups within the colony. The animals were then kept in individual cages, $26 \times 26 \times 28$ in., in an air-conditioned animal room and maintained on regular ad lib feeding. In their cages the monkeys could hear each other but could not directly see each other.

\section{APPARATUS}

The animals were observed in a specially constructed $6 \times 6 \times 4 \mathrm{ft} 3 / 8$-in. plywood cubicle, the inside of which was marked off

*This research was supported by a grant from the Florida Atlantic University Research Committee and in part by NICHD Grant HD1454. in 1 -ft squares by black lines $1 / 4$ in. in width. An additional $4-\mathrm{ft}$ width of green plastic screening was placed around the cubicle above the 4-ft walls. No monkeys were able to jump out over the screen walls. Social behavior was sampled at $3 \cdot \mathrm{sec}$ intervals over a $20-\mathrm{min}$ period by a Bolex 16-mm camera suspended on a bridge $11 \mathrm{ft}$ over the floor of the cubicle. With a wide-angle lens the entire cubicle could be photographed with the stationary camera. The camera shutter was operated by a solenoid mounted with the camera above the cubicie. The solenoid was activated by a ratchet-type interval switch. Next to the movie camera was mounted a TV monitoring camera with a cable lead to the receiver that was in the same room as the cubicle. The monkeys were not distracted by the visibility of any observers. Also suspended from the bridge was a microphone for tape recording vocalizations.

\section{PROCEDURE}

Two of the six monkeys were selected as target monkeys for interaction with the other four. These two monkeys, labeled X1 and $X 2$, were selected on the basis of

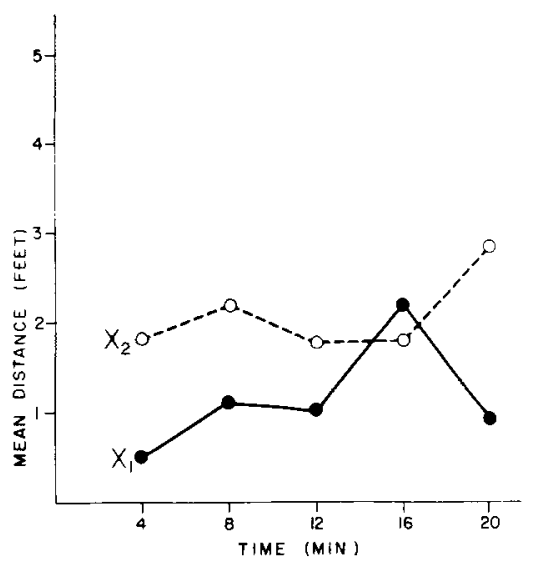

Fig. 1. Mean distance between Monkeys $X 1$ and $Y 1, Y 2, Y 3$, and $Y 4$ combined and Monkeys $\mathrm{X} 2$ and $Y 1, Y 2, Y 3$, and $Y 4$ combined, after 3 months' confinement. pretesting of the animals in the apparatus. The testing situation had mildly stressful characteristics; in addition to confinement in the cubicle with the black-lined squares, there was a periodic "thumping" when the solenoid was activated. $X 1$ and $X 2$ were selected as target monkeys because their behavior was more stable, as measured by an activity index, in this situation than was that of the other four. As part of the larger experiment, patterns of interaction in terms of approach-withdrawal tendencies were recorded for the first time 3 months after the beginning of confinement. X 1 formed a dyad with each of the other four monkeys that were labeled Y1, Y2, Y3, and $Y 4$. The same was done with $X 2$. Approach-withdrawal tendencies between each pair (i.e., X1 with Y1, X2 with Y1, etc.) were measured by inspecting each frame of the photographed interaction period of $20 \mathrm{~min}$. Since pictures of the interaction were taken at $3-\mathrm{sec}$ intervals, each interaction session yielded 400 frames for analysis. The least number of foot squares between the animals was taken as a measure of approach-withdrawal tendency. Patterns of interaction were observed again 4 months and 6 months after confinement. RESULTS AND DISCUSSION

The mean distance between the animals in 4-min intervals is presented in Figs. 1, 2, and 3 for each of the three testing periods. Each point on the plots represents the mean distance between $X 1$ or $X 2$ with $Y 1$, $\mathrm{Y}$, $\mathrm{Y} 3$, and $\mathrm{Y} 4$ combined. As the plots indicate, the social behavior of the animals changes drastically in the sixth month Whereas previously (i.e., at the third and fourth months of confinement) the animals would walk around the cubicle to explore it, at the sixth month of confinement they stayed very close to each other for the 20-min session. These data contradict

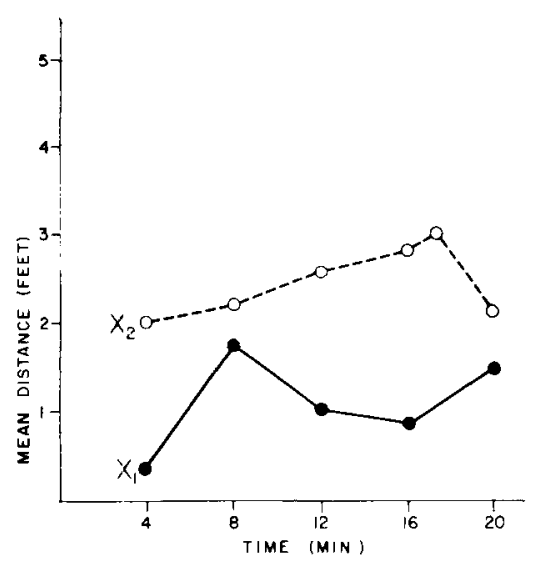

Fig. 2. Mean distance between Monkeys $X 1$ and $Y 1, Y 2, Y 3$, and $Y 4$ combined and Monkeys $\mathrm{X} 2$ and $Y 1, Y 2, Y 3$, and $Y 4$ combined, after 4 months' confinement. 


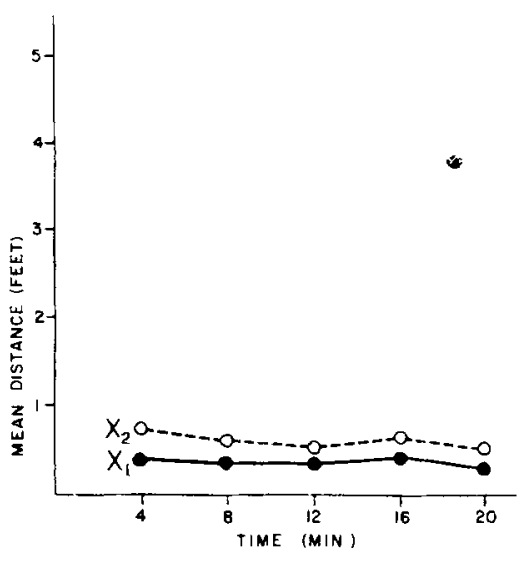

Fig. 3. Mean distance between Monkeys $X 1$ and $Y 1, Y 2, Y 3$, and $Y 4$ combined and Monkeys $X 2$ and $Y 1, Y 2, Y 3$, and $Y 4$ combined, after 6 months' confinement.

Cairns's (1966) hypothesis that "the strength of S's attachment with respect to $\mathrm{O}_{\mathrm{a}}$ should be inversely related to the length of separation from $\mathrm{O}_{a}$ " where $\mathrm{O}_{a}$ is the object of attachment. These results indicate that the length of confinement in cages for experimental studies on social behavior in monkeys should be explicitly taken in to account.

\section{REFERENCES}

CAIRNS, R. S. Attachment behavior of mammals. Psychological Review, 1966, 73, 409-426.

JOSLYN, W. D. Behavior of socially experienced juvenile rhesus monkeys after eight months of late social isolation and maternal separation in juvenile rhesus monkeys. Unpublished doctoral dissertation, Unviersity of Wisconsin, 1968.

MASON, W. A. The effects of social restriction on the behavior of rhesus monkeys: $I$. Free social behavior. Journal of Comparative \& Physiological Psychology, 1960, 53, 582-589. MASON, W. A. The effects of social restriction on the behavior of rhesus monkeys: II. Tests of gregariousness. Journal of Comparative \& Physiological Psychology, 1961, 54, 287-290.

MASON, W. A. The effects of social restriction on the behavior of rhesus monkeys: III. Dominance tests. Journal of Comparative \& Physiological Psychology, 1961, 54, 694-699. MOYER, K. E., \& KORN, J. H. Behavioral effects of isolation in the rat. Psychonomic Science, 1965, 3, 503-504.

SALAZAR, J. M. Gregariousness in young rats. Psychonomic Science, 1968, 10, 391-392.

\section{Inescapable shocks and subsequent escape/avoidance conditioning in goldfish. Carassius auratus}

\section{A. M. PADILLA, CHRISTINE PADILLA, TERRY KETTERER, and DIANE GIACALONE \\ State University of New York, Potsdam, N.Y. 13676}

Two experiments were conducted with goldfish, Carassius auratus, to assess the effects of inescapable shocks on subsequent escape/avoidance conditioning. Results indicate that inescapable shock presentations interfere with later avoidance training when Ss are tested 0,24 , and $48 \mathrm{~h}$ following inescapable shocks. However, the interference effect dissipates with time so that in $72 \mathrm{~h}$ Ss are capable of avoiding shock. The findings confirm the cross-species generality of the interference effect.

Overmier \& Seligman (1967) and Seligman \& Maier (1967) have shown that inescapable shocks interfere with the subsequent escape/avoidance conditioning of dogs. The interference effect has been obtained under a variety of shock parameters and with signaled and unsignaled inescapable shocks. Further, learning is not impaired if 48 to $72 \mathrm{~h}$ intervene between inescapable shocks and avoidance training (Overmier, 1968; Overmier \& Seligman, 1967).

Maier, Seligman, \& Solomon (1969) attribute the findings of depressed avoidance learning following inescapable shocks to learned helplessness. According to this interpretation, Ss' lack of control over the inescapable shocks results in a condition of helplessness. Indirect support for the generality of the interference effect has been shown across a wide variety of species (Maier et al, 1969).

The purpose of the present experiments was to extend the findings of Overmier and Seligman to a species considerably different from dogs. Specifically, the intent of the research was (1) to determine if the interference effect could be obtained with goldfish and (2) to investigate the time course of such an effect.

\section{EXPERIMENT 1}

The purpose of this experiment was to determine whether goldfish, given inescapable shocks, show a reduced rate of avoidance responding in a test session given $24 \mathrm{~h}$ after inescapable shocks.

Subjects and Apparatus

Thirty experimentally naive goldfish (Carassius auratus), 2-3 in. in length, were used. Ss were obtained from a local dealer and housed in a 55-gal tank for 1 week prior to the experiment.

Two Lafayette aquatic shuttlebox avoidance apparatuses (Model No. A-660) with the associated programmer timers and shock-generating control consoles were used. The shock level was set at $28 \mathrm{~V}$.

Procedure

Ss were randomly assigned to one of two groups ( $N=15$ per group). $S s$ in the experimental group were given 2 days of training. On Day 1 Ss were confined to one compartment of the apparatus and, following a 15-min adaptation period, were given 60 presentations of unsignaled and inescapable shock. Each shock was of $5 \mathrm{sec}$ duration. The interstimulus interval was $55 \mathrm{sec}$. Following inescapable shocks Ss were removed from the apparatus, returned to the storage tank, and confined in individual aquatic breeder nets. Approximately $24 \mathrm{~h}$ later Ss were given 25 trials of avoidance conditioning training. During this phase of the experiment, the shuttlebox was programmed so that the CS (light) preceded the US (shock) by $10 \mathrm{sec}$. If $S$ successfully avoided the US by swimming from the CS-on compartment to the safe compartment, the CS was manually terminated. If $S$ failed to avoid, the US was programmed for $5 \mathrm{sec}$. An escape response terminated both the CS and US. If $S$ failed to escape, the CS-US terminated automatically. The onset of each trial occurred $60 \mathrm{sec}$ after the onset of the CS on the preceding trial, regardless of whether $S$ had successfully avoided or escaped the US.

Ss in the second group served as controls. These Ss were given 25 trials of avoidance training only. $S s$ in both conditions were allowed $15 \mathrm{~min}$ of adaptation to the shuttlebox apparatus prior to any avoidance training.

\section{Results}

Table 1 summarizes the avoidance performance data. Analyses revealed that the control Ss differed significantly from the experimental $\mathrm{Ss}$ both in mean avoidance responses and mean number of trials to the first avoidance response $(t=4.62$ and 3.98 , respectively, $\mathrm{d} f=28$, $p<.01)$. However, the two groups did not 